\title{
Variabilidade genética em tambaquis (Teleostei: Characidae) de diferentes regiões do Brasil
}

\author{
Carolina Bespalhok Jacometo(1), Nelson Maurício Lopera Barrero(2), Maria Del Pilar Rodriguez-Rodriguez(1), \\ Patrícia Cristina Gomes ${ }^{(1)}$, Jayme Aparecido Povh (2), Danilo Pedro Streit Junior( ${ }^{(3)}$, \\ Lauro Vargas ${ }^{(1)}$, Emiko Kawakami de Resende ${ }^{(4)}$ e Ricardo Pereira Ribeiro ${ }^{(1)}$
}

\begin{abstract}
(1)Universidade Estadual de Maringá, Departamento de Zootecnia, Avenida Colombo, oo 5.790, Bloco J45, CEP $87020-900$ Maringá, PR. E-mail: carolina.peixegen@gmail.com, rodrigpilar@gmail.com, patriciacristinagomes@hotmail.com, Ivargas@uem.br, rpribeiro@uem.br (2)Universidade Federal do Mato Grosso, Núcleo de Pesquisa PeixeGen e Aquapeq, Rodovia Rondonópolis, Km 6, CEP 78735-901 Rondonópolis, MT. E-mail: nelson.peixegen@gmail.com, jayme.peixegen@gmail.com ${ }^{(3)}$ Universidade Federal do Rio Grande do Sul, Departamento de Zootecnia, Avenida Bento Gonçalves, № 7.712, CEP 915400-000 Porto Alegre, RS. E-mail: danilo.streit@ufrgs.br (4)Embrapa Pantanal, Rua 21 de Setembro, no 1.880, CEP79320-900 Corumbá, MS. E-mail: emiko@cpap.embrapa.br
\end{abstract}

Resumo - O objetivo deste trabalho foi avaliar a diversidade genética em quatro estoques de tambaquis (Colossoma macropomum) de diferentes regiões do Brasil, por meio de marcador RAPD. Foram utilizados 10 iniciadores para analisar 116 indivíduos, coletados de pisciculturas nos municípios de Urupá, RO, Teixeirópolis, RO, Neópolis, SE e Sorriso, MT. Foram encontradas diferenças nas frequências de 67 fragmentos, com um fragmento exclusivo em Sorriso e dois em Neópolis. Observaram-se altos valores de polimorfismo (72,92 a $83,33 \%)$, diversidade genética de Nei $(0,27$ a 0,30$)$ e índice de Shannon $(0,39$ a 0,45$)$. A análise da variância molecular, demonstrou que a maior parte da variação está dentro de cada estoque e não entre os estoques. A identidade e a distância genética entre os agrupamentos variou de 0,93 a 0,98 e 0,02 a 0,07, respectivamente, com menos distância entre os agrupamentos Urupá x Sorriso e entre Teixerópolis x Neópolis. A diferenciação genética variou de baixa a moderada $\left(\mathrm{F}_{\mathrm{st}}=0,03\right.$ a 0,15$)$ e o número de migrantes por geração foi alto $(\mathrm{Nm}=5,96$ a 24,3), entre os agrupamentos. Os estoques apresentam alta variabilidade e baixa diferenciação e distância genética entre si.

Termos para indexação: Colossoma macropomum, diversidade genética, RAPD.

\section{Genetic variability of tambaqui (Teleostei: Characidae) from different regions of Brazil}

\begin{abstract}
The objective of this study was to evaluate the genetic diversity of four broodstocks of tambaqui (Colossoma macropomum) from different regions of Brazil using RAPD markers. Ten primers were used to analyze 116 individuals, collected from fish cultures of three municipalities in Brazil: Urupá, RO; Teixeirópolis, RO; Neópolis, SE; and Sorriso, MT. Differences in the frequencies of 67 fragments were found, with a unique fragment in Sorriso and two in Neópolis. High values of polymorphism (72.92 to 83.33\%), Nei's genetic diversity (from 0.27 to 0.30 ) and Shannon index (from 0.39 to 0.45 ) were observed. Analysis of molecular variance showed that most of the variation is within each broodstock and not among them. The identity and genetic distance among the groups ranged from 0.93 to 0.98 and from 0.02 to 0.07 , respectively, with less distance between clusters Urupá x Sorriso and Teixerópolis x Neópolis. Genetic differentiation ranged from low to moderate $\left(\mathrm{F}_{\mathrm{st}}=0.03\right.$ to 0.15$)$ and the number of migrants per generation was high ( $\mathrm{Nm}=5.96$ to 24.3$)$ among the groups. Stocks have high variability and low genetic differentiation and distance among them.
\end{abstract}

Index terms: Colossoma macropomum, genetic diversity, RAPD.

\section{Introdução}

A produção brasileira da aquicultura continental foi de 191.183,5 Mg, em 2007 (Instituto Brasileiro do Meio Ambiente e dos Recursos Naturais Renováveis, 2008). As principais espécies de peixes utilizadas na aquicultura das Regiões Norte, Nordeste e Centro-Oeste são tilápia, carpa, tambaqui, tambacu e curimatã.
O tambaqui (Colossoma macropomum) foi a espécie nativa com maior produção aquícola $(26.662 \mathrm{Mg})$, atrás apenas das espécies exóticas tilápia (Oreochromis niloticus) (71.253 Mg) e carpa-comum (Cyprinus carpio) (45.831,5 Mg), em 2007.

A espécie Colossoma macropomum pertence à ordem Characiformes e à família Characidae e ocorre naturalmente nas bacias dos Rios Amazonas e Orinoco, 
na Região Norte do país. Por ser uma espécie reofílica e não se reproduzir espontaneamente em tanques, a utilização de hormônios para a sua reprodução é necessária. Dessa forma, o manejo adequado do plantel de reprodutores é a chave para o sucesso reprodutivo em criações (Araújo-Lima \& Gomes, 2005).

Existem diversos fatores que favorecem a criação de tambaqui, como fácil obtenção de juvenis, bom potencial de crescimento, alta produtividade e rusticidade (Araújo-Lima \& Goulding, 1997). Portanto, o interesse em se estabelecer um pacote tecnológico para a criação da espécie é grande (Gomes et al., 2003). Atualmente, de cada cinco tambaquis consumidos, quatro são provenientes de cativeiro. Dessa forma, a piscicultura garante o abastecimento a preço baixo.

Para que programas de conservação e produção de peixes apresentem resultados satisfatórios imediatos e de longo prazo, é necessário realizar o monitoramento genético dessas populações (Lopera Barrero et al., 2009). Estudos demonstram que a diminuição da variabilidade genética em estoques de pisciculturas ocorre principalmente por manejo reprodutivo inadequado (Frost et al., 2006), deficiência no número efetivo de reprodutores (Aho et al., 2006) e seleção não intencional. $O$ resultado dessas ações pode causar problemas de endogamia, adaptabilidade e sobrevivência das progênies (Povh et al., 2008a). Além disso, a variabilidade genética é fundamental para qualquer programa de melhoramento genético (Falconer, 1987). Portanto, a identificação do grau de variabilidade nos estoques de reprodutores é de grande importância para iniciar um programa de melhoramento (Lopes et al., 2009), pois o potencial evolutivo e de melhoramento depende da variabilidade genética (Melo et al., 2006). Assim, a correta identificação de estoques pode servir como ferramenta para o estabelecimento de bases de seleção, em programas de melhoramento. Este aspecto pode ser utilizado para aumentar a variabilidade genética e explorar positivamente o efeito da heterose (Mather, 2001).

Os marcadores moleculares são ferramentas importantes na análise da diversidade genética. Ultimamente, a técnica de RAPD ("Random Amplified Polymorphic DNA") tem sido um eficiente instrumento utilizado em estudos de diversidade genética de peixes (Liu \& Cordes, 2004), em razão do seu alto potencial de detecção de polimorfismo (Ali et al., 2004) e por se basear na PCR ("Polymerase Chain Reaction"), que é uma ferramenta simples, rápida e eficiente (Ferreira \& Grattapaglia, 1998).

O objetivo deste trabalho foi avaliar a diversidade genética de estoques do peixe C. macropomum de diferentes Regiões do Brasil, por meio de marcador molecular RAPD.

\section{Material e Métodos}

Foram coletadas amostras de nadadeira caudal dos estoques de reprodutores de $C$. macropomum provenientes de pisciculturas dos municípios de Urupá, RO (URO, 30 indivíduos), Teixeirópolis, RO (TRO, 30 indivíduos), Neópolis, SE (NSE, 26 indivíduos) e Sorriso, MT (SMT, 30 indivíduos). O trabalho foi desenvolvido no Laboratório de Biologia Molecular do Departamento de Zootecnia da Universidade Estadual de Maringá, Maringá, PR, de janeiro a abril de 2009.

Para extração de DNA, foi utilizada a metodologia descrita por Lopera Barrero et al. (2008a). Em microtubos que continham aproximadamente $0,5 \mathrm{~cm}^{2}$ das amostras de nadadeiras, foram adicionados $550 \mu \mathrm{L}$ de tampão de lise $\left(50 \mathrm{mmol} \mathrm{L}^{-1}\right.$ Tris- $\mathrm{HCl}$, $50 \mathrm{mmol} \mathrm{L}{ }^{-1}$ EDTA, $100 \mathrm{mmol} \mathrm{L}^{-1} \mathrm{NaCl}$ e $1 \%$ SDS) e $7 \mu \mathrm{L}$ de proteinase $\mathrm{K}\left(200 \mathrm{mg} \mu \mathrm{L}^{-1}\right)$. Esse material foi incubado em banho-maria a $50^{\circ} \mathrm{C}$ por 12 horas.

O DNA foi precipitado com $600 \mu \mathrm{L}$ de solução de $\mathrm{NaCl}\left(5 \mathrm{~mol} \mathrm{~L}^{-1}\right)$ e centrifugado por $10 \mathrm{~min}$ a $14.645 \mathrm{~g}$. O sobrenadante com o DNA foi transferido para novos microtubos $(800 \mu \mathrm{L})$, precipitado com $700 \mu \mathrm{L}$ de álcool etílico absoluto e incubado por 1 hora a $-20^{\circ} \mathrm{C}$. Em seguida, o DNA foi centrifugado, lavado com $700 \mu \mathrm{L}$ de álcool etílico a $70 \%$, suspendido em $85 \mu \mathrm{L}$ de tampão TE $\left(10 \mathrm{mmol} \mathrm{L}^{-1}\right.$ Tris $\mathrm{pH} 8 \mathrm{e} 1 \mathrm{mmol} \mathrm{L}^{-1}$ EDTA) e tratado com $7 \mu \mathrm{L}$ de RNAse $\left(30 \mathrm{mg} \mathrm{mL}^{-1}\right)$ em banho-maria, a $37^{\circ} \mathrm{C}$, por 1 hora. Após a realização desses procedimentos, a substância foi estocada em freezer a $-20^{\circ} \mathrm{C}$.

O DNA foi quantificado em espectrofotômetro Shimadzu (Shimadzu Corporation, Kyoto, Japão) com absorbância de $260 \mathrm{~nm}$. As amostras foram diluídas para uma concentração de $10 \mathrm{ng} \mu \mathrm{L}^{-1}$. Para conferir a qualidade do DNA extraído, foi realizada uma eletroforese em gel de agarose a $1 \%$, conduzida em tampão TBE 1X (500 mmol L-1 Tris- $\mathrm{HCl}, 60 \mathrm{mmol} \mathrm{L}^{-1}$ ácido bórico e $83 \mathrm{mmol} \mathrm{L}^{-1}$ EDTA), por 1 hora, a 70 volts. 
As condições de amplificação foram baseadas em procedimentos descritos por Williams et al. (1990) com modificações. O DNA foi amplificado em um volume de reação de $15 \mu \mathrm{L}$, no qual se utilizou tampão $1 X$ Tris-KCl, 2 mmol L-1 de $\mathrm{MgCl}_{2}, 0,46 \mu \mathrm{mol} \mathrm{L}^{-1}$ de iniciador, 0,2 $\mathrm{mmol} \mathrm{L}^{-1}$ de cada $\mathrm{dNTP}$, uma unidade de Platinum Taq DNA Polimerase (Invitrogen, Carlsbad, EUA), e 10 ng de DNA alvo. O DNA foi desnaturado a $94^{\circ} \mathrm{C}$ por 4 min e, em seguida, foram realizados 40 ciclos, cada um consistindo de 1 min de desnaturação a $94^{\circ} \mathrm{C}, 30 \mathrm{~s}$ de anelamento do iniciador a $40^{\circ} \mathrm{C}$, e $2 \mathrm{~min}$ para extensão a $72^{\circ} \mathrm{C}$.

Em seguida, realizou-se uma extensão final a $72^{\circ} \mathrm{C}$ por $7 \mathrm{~min}$. As reações de RAPD foram amplificadas em um termociclador Eppendorf Mastercycler Gradient. Foram escolhidos 10 diferentes iniciadores, com 10 bases, dos Kits OPA, OPW e OPX (Operon Technologies Ltd., Valencia, EUA), que apresentaram melhor definição e reprodutibilidade: OPA01, OPA02, OPA16, OPW02, OPW03, OPW04, OPW08, OPX02, OPX02, OPX04.

Os produtos de amplificação foram separados em gel de agarose a 1,5\%. Foram utilizados $15 \mu \mathrm{L}$ do produto amplificado e $2 \mu \mathrm{L}$ de tampão de amostra (40\% sacarose e $0,25 \%$ azul de bromofenol) em eletroforese horizontal. A eletroforese foi conduzida em tampão TBE 0,5X (45 mmol L $\mathrm{L}^{-1}$ Tris-Borato e $1 \mathrm{mmol} \mathrm{L}^{-1}$ EDTA) por 4 horas, a 70 volts. Os géis de quantificação e amplificação foram visualizados sob radiação UV, depois da sua exposição com brometo de etídio $\left(0,5 \mu \mathrm{g} \mathrm{mL}^{-1}\right)$ por 1 hora. A imagem foi fotografada com uso do programa Kodak EDAS (Kodak 1D Image Analysis 3.5, New York, EUA).

O tamanho dos fragmentos obtidos com as amplificações foi estimado por comparação com o padrão ladder 100 pb (Invitrogen, Carlsbad, EUA). A presença ou ausência de fragmentos de tamanhos moleculares idênticos foi usada para a construção de uma matriz de similaridade com base no cálculo do coeficiente de similaridade de Jaccard, tendo-se codificado " 1 " como presença de fragmento e " 0 " como ausência. O índice de diversidade genética de Shannon, a diversidade genética de Nei (1973) e o dendrograma de distância genética de Nei (1978) foram obtidos com o programa PopGene 1.31 (Yeh et al., 1999).

O programa TFPGA 1.3 (Miller, 1997) foi utilizado para determinar a percentagem de fragmentos polimórficos (critério de 95\%), distância e identidade genética (Nei, 1978) entre os estoques e frequência dos fragmentos pelo teste exato (Raymond \& Rousset, 1995). O programa Arlequin 3.0 (Excoffier et al., 2005) foi utilizado para determinar a diferenciação genética por meio das estimativas de $\mathrm{F}_{\text {st }}$ (coeficiente de ancestria) (Weir \& Cockerham, 1984), e para análise de variância molecular (Excoffier et al., 1992). Para analisar a variância molecular entre os estoques, eles foram agrupados dois a dois, com todas as combinações possíveis, assim distribuídos: Urupá x Teixeirópolis; Urupá x Neópolis; Urupá x Sorriso; Teixeirópolis x Neópolis; Teixeirópolis x Sorriso; Neópolis x Sorriso.

A significância desses testes foi verificada pelo método de permutações aleatórias, com uso de 1.000 e 10.000 permutações. Esse programa também foi utilizado para determinar o número de migrantes por geração $(\mathrm{Nm})$. A significância estatística do $\mathrm{F}_{\mathrm{st}}$ foi obtida pelo teste $\mathrm{X}^{2}\left[\mathrm{c}^{2}=2 \mathrm{n}\right.$ FST (k-1); $\mathrm{GL}=(\mathrm{k}-1)(\mathrm{s}-1)]$, proposto por Workman \& Niswander (1970), em que: n é o número de indivíduos nos dois grupos, $\mathrm{k}$ é o número de alelos e $\mathrm{s}$, o número de grupos. A magnitude de diferenciação genética entre os estoques foi determinada segundo a definição de Wright (1978), para caracterizar como baixa $\left(\mathrm{F}_{\mathrm{st}}=0\right.$ a 0,05$)$, moderada $\left(\mathrm{F}_{\mathrm{st}}=0,05\right.$ a 0,15$)$, alta $\left(\mathrm{F}_{\mathrm{st}}=0,15\right.$ a 0,25$)$ e muito alta $\left(\mathrm{F}_{\mathrm{st}}>0,25\right)$.

\section{Resultados e Discussão}

Os dez iniciadores selecionados geraram 144 fragmentos, que variaram de 12 , para o iniciador OPW04, a 17 para o OPA02. O fragmento maior $(2.500 \mathrm{pb})$ e o menor $(200 \mathrm{pb})$ foram obtidos por meio da amplificação com os iniciadores OPX01 e OPW02, respectivamente. Dos 144 fragmentos obtidos, 135 $(93,75 \%)$ eram polimórficos (Tabela 1$)$.

Foram observadas diferenças $(\mathrm{p}<0,05)$ na frequência de 67 dos 144 fragmentos. Fragmentos com baixa frequência (menor que 0,1000 ) foram observados em todos os estoques (URO, 4; TRO, 3; NSE, 5; e SMT, 2) e 76 estiveram ausentes (frequência de 0,0000 ) nos diferentes estoques (URO, 26; TRO, 17; NSE, 12; e SMT, 21) (Figura 1). As baixas frequências, bem como a ausência desses fragmentos dentro de cada estoque, fatores que afetam a variabilidade genética, pode ser explicada pelo efeito "bottleneck" provocado pela seleção não intencional que se verifica durante os processos reprodutivos realizados em pisciculturas. 
Esses processos que normalmente incluem a seleção de indivíduos com as melhores características fenotípicas ou reprodutivas podem levar ao acasalamento entre indivíduos geneticamente aparentados e gerar perda de variabilidade (Moreira et al., 2007).

Outro fator que pode ter influenciado é o efeito fundador. Se o estoque for formado com poucos indivíduos ou os indivíduos selecionados não representarem geneticamente as populações originais, pode haver perda de variabilidade genética, que vai ocasionar a presença de baixas frequências ou ausência de fragmentos. Contudo, não é possível afirmar concretamente se esses dois fatores influenciaram as

Tabela 1. Sequência dos iniciadores e de nucleotídeos, porcentagem de bases púricas $(\mathrm{G}+\mathrm{C})$, e número e pares de bases dos fragmentos observados nos estoques de Colossoma macropomum.

\begin{tabular}{lcccc}
\hline Iniciador & $\begin{array}{c}\text { Sequência de } \\
\text { nucleotídeos }\end{array}$ & $(\mathrm{G}+\mathrm{C})$ & $\begin{array}{c}\mathrm{N}^{\mathbf{0}} \text { de } \\
\text { fragmentos }\end{array}$ & Pares de bases \\
\hline OPA01 & CAG GCC CTT C & 70 & 14 & $300-2.072$ \\
OPA02 & TGC CGA GCT G & 70 & 17 & $220-2.072$ \\
OPA16 & AGC CAG CGA A & 60 & 15 & $290-2.150$ \\
OPW02 & ACC CCG CCA A & 70 & 15 & $200-1.850$ \\
OPW03 & GTC CGG AGT G & 70 & 14 & $300-2.072$ \\
OPW04 & CAG AAG CGG A & 60 & 12 & $230-2.072$ \\
OPW08 & GAC TGC CTC T & 60 & 14 & $480-2.200$ \\
OPX01 & CTG GGC ACG A & 70 & 13 & $300-2.500$ \\
OPX02 & TTC CGC CAC C & 70 & 14 & $310-2.100$ \\
OPX04 & CCG CTA CCG A & 70 & 16 & $390-2.200$ \\
\hline Total & - & - & 144 & $200-2.500$ \\
\hline
\end{tabular}

frequências, pois não existem informações do manejo reprodutivo realizado dentro de cada piscicultura nem da origem desses indivíduos.

Foram encontrados 12 fragmentos limitantes (frequência de 1,000) distribuídos de forma diferente dentro de cada estoque (URO, 4; TRO, 2; NSE, 1; e SMT, 5) e três fragmentos exclusivos para os estoques SMT (OPX01, $2.500 \mathrm{pb}$ ) e NSE (OPA02, 220-450pb). Esses resultados são indicação de que, apesar de os estoques apresentarem fragmentos com baixa frequência e ausentes, existe alta variabilidade genética dentro de cada estoque.

A variabilidade genética dentro dos estoques (Tabela 2) mostrou valores adequados de variabilidade, o que está de acordo com os resultados obtidos nas frequências. É esperado que, em estoques mantidos em cativeiro, exista uma diminuição da variabilidade genética, em consequência do efeito da seleção intencional e do acasalamento entre parentais (Lopera Barrero et al., 2010), porém, os resultados do presente estudo não contêm evidências de grande perda de variabilidade genética.

Outros autores, que têm pesquisado a variabilidade genética de espécies nativas brasileiras mantidas em cativeiro, relataram resultados semelhantes aos encontrados no presente estudo. Lopes et al. (2009) analisaram dois estoques de C. macropomum, oriundos do Estado de Rondônia, e encontraram valores maiores

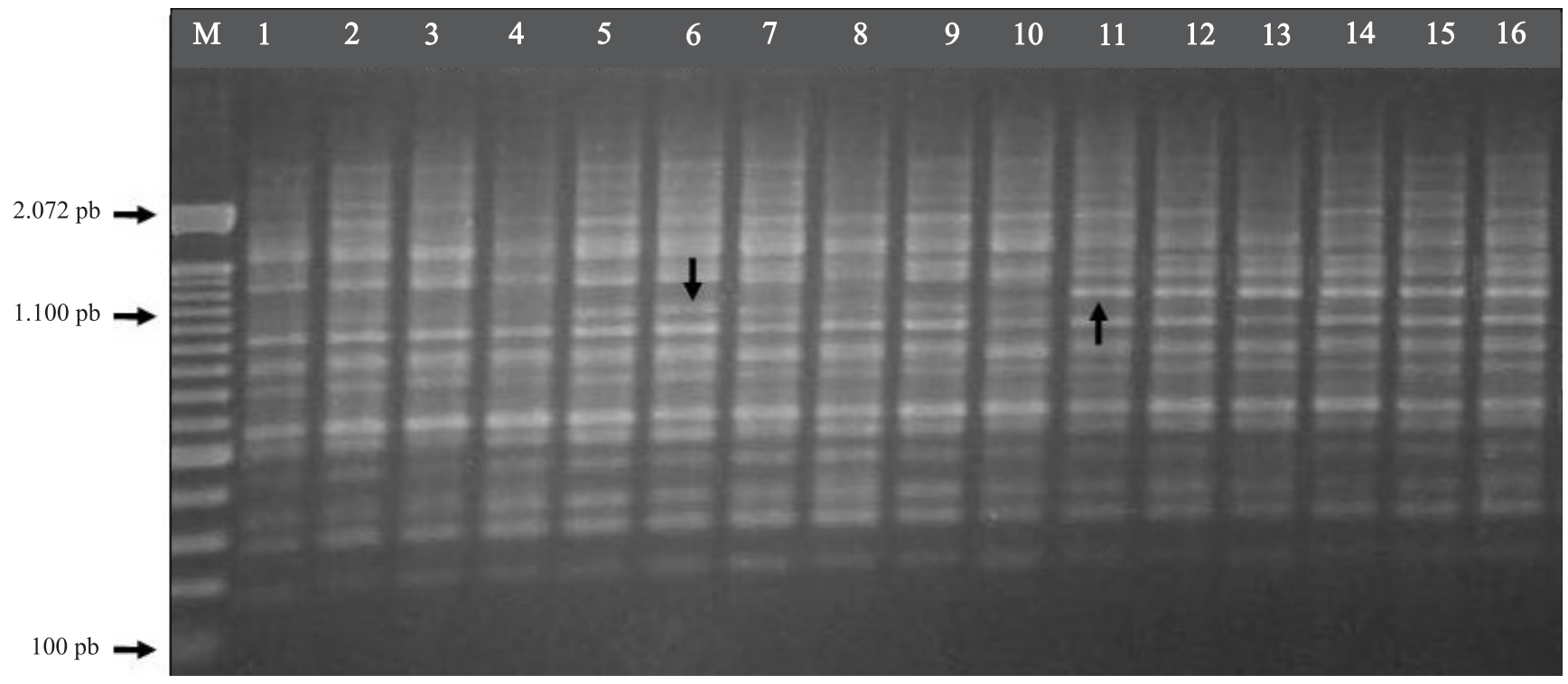

Figura 1. Gel de agarose a 1,5\% do iniciador OPA16, com caracterização de um fragmento de 1.100 pb, excluído no estoque de Colossoma macropomum de Urupá, RO (amostras 11 a 16). Amostras de 1 a 10, estoque de Sorriso, MT. M, marcador de peso molecular. 
para o índice de Shannon $(0,47$ e 0,44$)$ e percentagem de fragmentos polimórficos (77,0 e 75,0), e concluíram que existe alta variabilidade genética. Lopera Barrero et al. (2008b) analisaram dois estoques de Prochilodus lineatus, e também encontraram valores superiores para índice de Shannon $(0,47$ e 0,46$)$ e percentagem de fragmentos polimórficos $(83,12$ e 81,82$)$. Por sua vez, Povh et al. (2008b), ao analisar um estoque de Piaractus mesopotamicus, observaram valores inferiores aos do presente trabalho, quanto ao índice de Shannon e percentagem de fragmentos polimórficos (0,29 e 56,53, respectivamente), e atribuíram esse resultado a um manejo inadequado dos reprodutores daqueles plantéis.

Por meio das análises comparativas dos diferentes agrupamentos, observou-se que a maior parte da

Tabela 2. Índice de Shannon (IS), diversidade genética de Nei (1973) e porcentagem de fragmentos polimórficos (FP) para os estoques de Colossoma macropomum.

\begin{tabular}{lcccc}
\hline Estoques & Número de indivíduos & IS & Nei & FP \\
\hline Urupá, RO & 30 & 0,39 & 0,27 & 72,92 \\
Teixeirópolis, RO & 30 & 0,45 & 0,30 & 82,64 \\
Neópolis, SE & 26 & 0,45 & 0,30 & 83,33 \\
Sorriso, MT & 30 & 0,40 & 0,27 & 73,61 \\
\hline
\end{tabular}

variação está dentro de cada estoque e não entre os estoques de C. macropomum (Tabela 3). A distância e a identidade genética entre estoques mostraram que existe maior semelhança entre URO x SMT e TRO x NSE, o que foi evidenciado pelos valores de $\mathrm{F}_{\mathrm{ST}}$, de 0,03 e 0,05 , respectivamente, que, segundo a definição de Wright (1978), são indicação de baixa diferenciação genética. Os outros agrupamentos apresentaram moderada diferenciação, com alto número de migrantes (Nm) (Tabela 4). Não é possível saber como se formaram os estoques iniciais de C. macropomum, pois não existem informações sobre a origem desses indivíduos. Lopes et al. (2009) também encontraram alto número de migrantes por geração $(13,35)$ para C. macropomum, o que sugere a existência de um fluxo gênico entre esses estoques, com um reservatório de genes semelhantes.

O marcador molecular RAPD pode ser utilizado com sucesso na avaliação do nível de variabilidade genética de estoques mantidos em cativeiro, já que permite obter um perfil genético dos indivíduos estudados. Entretanto, deve-se considerar a realização de outras investigações com uso de novas técnicas moleculares que permitam a obtenção de mais informações.

Tabela 3. Análise de variância molecular, para os diferentes agrupamentos utilizados nas populações de Colossoma macropomum $^{(1)}$.

\begin{tabular}{|c|c|c|c|c|c|}
\hline Fonte de variação & Quadrado médio & $\mathrm{CV}(\%)$ & Variação (\%) & Distância & Identidade genética \\
\hline & \multicolumn{5}{|c|}{ Urupá, RO x Teixeirópolis, RO } \\
\hline Entre estoques & 78,550 & 2,01720 & $10,06^{*}$ & 0,0465 & 0,9546 \\
\hline Dentro de estoques & $1.045,967$ & 18,03391 & 89,94 & - & - \\
\hline \multirow[t]{2}{*}{ Total } & $1.124,517$ & 20,05111 & 100,00 & - & - \\
\hline & \multicolumn{5}{|c|}{ Urupá, RO x Neópolis, SE } \\
\hline Entre estoques & 93,115 & 2,76099 & $14,56^{*}$ & 0,0579 & 0,9438 \\
\hline Dentro de estoques & 874,903 & 16,20190 & 85,44 & - & - \\
\hline \multirow[t]{2}{*}{ Total } & 968,018 & 18,96289 & 100,00 & - & - \\
\hline & \multicolumn{5}{|c|}{ Urupá, RO x Sorriso, MT } \\
\hline Entre estoques & 28,450 & 0,45270 & $2,95^{*}$ & 0,0176 & 0,9835 \\
\hline Dentro de estoques & 862,400 & 14,86897 & 97,05 & & \\
\hline \multirow[t]{2}{*}{ Total } & 890,850 & 15,32167 & 100,00 & - & - \\
\hline & \multicolumn{5}{|c|}{ Teixeirópolis, RO x Neópolis, SE } \\
\hline Entre estoques & 21,566 & 0,42514 & $4,19^{*}$ & 0,0180 & 0,9822 \\
\hline Dentro de estoques & 525,041 & 9,72298 & 95,81 & - & - \\
\hline \multirow[t]{2}{*}{ Total } & 546,607 & 10,14812 & 100,00 & - & - \\
\hline & \multicolumn{5}{|c|}{ Teixeirópolis, RO x Sorriso, MT } \\
\hline Entre estoques & 72,467 & 1,96619 & $12,73^{*}$ & 0,0546 & 0,9469 \\
\hline Dentro de estoques & 781,900 & 13,48103 & 87,27 & - & - \\
\hline \multirow[t]{2}{*}{ Total } & 854,367 & 15,44722 & 100,00 & - & - \\
\hline & \multicolumn{5}{|c|}{ Neópolis, SE x Sorriso, MT } \\
\hline Entre estoques & 74,371 & 2,20657 & $14,60 *$ & 0,0701 & 0,9323 \\
\hline Dentro de estoques & 696,736 & 12,90250 & 85,40 & - & - \\
\hline Total & 771,107 & 15,10910 & 100,00 & - & - \\
\hline
\end{tabular}

*Significativo a $5 \%$ de probabilidade. 
Tabela 4. Coeficiente de ancestria $\left(\mathrm{F}_{\mathrm{st}}\right)$, teste de $\mathrm{X}^{2}$ para o $\mathrm{F}_{\mathrm{st}}$, diferenciação genética segundo Wright (1978) e número de migrantes $(\mathrm{Nm})$, para os diferentes agrupamentos analisados nas populações de Colossoma macropomum.

\begin{tabular}{lccrr}
\hline Agrupamentos & $\mathrm{F}_{\mathrm{ST}}$ & Wright & \multicolumn{1}{c}{$\mathrm{X}^{2}$} & $\mathrm{Nm}$ \\
\hline Urupá, RO x Teixeirópolis, RO & $0,1006^{*}$ & Moderada & 12,0720 & 8,72 \\
Urupá, RO x Neópolis, SE & $0,1456^{*}$ & Moderada & 16,3070 & 7,01 \\
Urupá, RO x Sorriso, MT & $0,0295^{*}$ & Baixa & 3,5400 & 16,20 \\
Teixeirópolis, RO x Neópolis, SE & $0,0419^{*}$ & Baixa & 4,6928 & 24,30 \\
Teixeirópolis, RO x Sorriso, MT & $0,1273^{*}$ & Moderada & 15,2760 & 7,60 \\
Neópolis, SE x Sorriso, MT & $0,1460^{*}$ & Moderada & 16,3520 & 5,96 \\
\hline
\end{tabular}

\section{Conclusões}

1. Os estoques de tambaqui das regiões analisadas apresentam alta variabilidade genética, com maiores valores em Teixeirópolis, RO, e em Neópolis, SE.

2. Os estoques de tambaqui das regiões analisadas apresentam moderada diferenciação e baixa distância genética entre si.

\section{Agradecimentos}

Aos integrantes do Núcleo de Pesquisa PeixeGen, pelo auxílio no desenvolvimento do trabalho; ao Conselho Nacional de Desenvolvimento Científico e Tecnológico, à Secretaria Especial de Aquicultura e Pesca do Paraná; e à Empresa Brasileira de Pesquisa Agropecuária pelo apoio financeiro; aos proprietários das fazendas de pisciculturas, pelo fornecimento de indivíduos dos estoques de reprodutores de Colossoma macropomum.

\section{Referências}

AHO, T.; RÖNN, J.; PIIRONEN, J.; BJÖRKLUND, M. Impacts of effective population size on genetic diversity in hatchery reared Brown trout (Salmo trutta L.) populations. Aquaculture, v.253, p.244-248, 2006.

ALI, B.A.; HUANG, T.H.; QIN, D.N.; WANG, X.M. A review of random amplified polymorphic DNA (RAPD) markers in fish research. Reviews in Fish Biology and Fisheries, v.14, p.443-453, 2004.

ARAÚJO-LIMA, C.A.R.M.; GOMES, L. de C. Tambaqui (Colossoma macropomum). In: BALDISSEROTTO, B.; GOMES, L. de C. Espécies nativas para piscicultura no Brasil. Santa Maria: UFSM, 2005. p.67-104.

ARAÚJO-LIMA, C.A.R.M.; GOULDING, M. So fruitful fish: ecology, conservation, and aquaculture of the Amazon's Tambaqui. New York: Columbia University, 1997. 157p.

EXCOFFIER, L.; LAVAL, G.; SCHNEIDER, S. Arlequin (version 3.0): an integrated software package for population genetics data analysis. Evolutionary Bioinformatics Online, v.1, p.47-50, 2005.

EXCOFFIER, L.; SMOUSE, P.E.; QUATTRO, J.M. Analysis of molecular variance inferred from metric distances among DNA haplotypes: application to human mitochondrial DNA restriction data. Genetics, v.131, p.479-491, 1992.

FALCONER, D.S. Introdução a genética quantitativa. Viçosa: UFV, 1987. 279p.

FERREIRA, M.E.; GRATTAPAGLIA, D. Introdução ao uso de marcadores moleculares em análise genética. 3.ed. Brasília: Embrapa Cenargen, 1998. 220p. (Embrapa Cenargen. Documentos, 20).

FROST, L.A.; EVANS, B.S.; JERRY, D.R. Loss of genetic diversity due to hatchery culture practices in barramundi (Lates calcarifer). Aquaculture, v.261, p.1056-1064, 2006.

GOMES, L. de C.; ARAÚJO-LIMA, C.A.R.M.; ROUBACH, R.; URBINATI, E.C. Avaliação dos efeitos da adição de sal e da densidade no transporte de tambaqui. Pesquisa Agropecuária Brasileira, v.38, p.283-290, 2003.

INSTITUTO BRASILEIRO DO MEIO AMBIENTE E DOS RECURSOS NATURAIS RENOVÁVEIS. Estatísticas da pesca 2006 Brasil: grandes regiões e unidades da federação. Brasília: IBAMA, 2008. 174p.

LIU, Z.J.; CORDES, J.F. DNA marker technologies and their applications in aquaculture genetics. Aquaculture, v.238, p.1-37, 2004.

LOPERA BARRERO, N.M.; POVH, J.A.; RIBEIRO, R.P.; GOMES, P.C.; JACOMETO, C.B.; LOPES, T. da S. Comparación de protocolos de extracción de $\mathrm{ADN}$ con muestras de aleta y larva de peces: extracción modificada con cloruro de sodio. Ciencia e Investigación Agraria, v.35, p.15-24, 2008a.

LOPERA BARRERO, N.M.; RIBEIRO, R.P.; POVH, J.A.; VARGAS, L.; JACOMETO, C.B.; GOMES, P.C. Diversidad genética de lotes de Piaractus mesopotamicus usados em programas de repoblamiento y sus implicaciones en la conservación. Agrociencia, v.43, p.249-256, 2009.

LOPERA BARRERO, N.M.; RIBEIRO, R.P.; VARGAS, L.; POVH, J.A.; GOMES, P.C.; MANGOLIN, C.A.; BOSO, K.M.O.; GUALDA, T. Caracterização genética de estoques de Prochilodus lineatus (Valenciennes, 1836) (Characiformes: Prochilodontidae), utilizados em programas de repovoamento: importância para a conservação da ictiofauna e do ecossistema. Bioscience Journal, v.24, p.86-93, 2008b.

LOPERABARRERO, N.M.; RIBEIRO, R.P.; VARGAS, L.; POVH, J.A.; LOPES, T.S.; OLIVEIRA, S.N.; GOMES, P.C. Diversidad genética de Piaractus mesopotamicus utilizado em programas de repoblación. Archivos de Zootecnia, v.59, p.51-62, 2010.

LOPES, T.S.; STREIT JUNIOR, D.P.; RIBEIRO, R.P.; POVH, J.A.; LOPERA BARRERO, N.M.; VARGAS, L.; PINTO FILHO, C.; QUEIROZ, J.R. Diversidade genética de estoques de reprodutores de Colossoma macropomum. Arquivo Brasileiro de Medicina Veterinária e Zootecnia, v.61, p.728-735, 2009.

MATHER, P.B. Overview of fish genetics research at Queensland University of Technology. In: GUPTA, M.V.; ACOSTA, B.O. (Ed.). 
Fish genetics research in member countries and institutions of the International Network on Genetics in Aquaculture. Penang: The World Fish Center, 2001. p.133-139.

MELO, D.C.; OLIVEIRA, D.A.A.; RIBEIRO, L.P.; TEIXEIRA, C.S.; SOUSA, A.B.; COELHO, E.G.A.; CREPALDI, D.V.; TEIXEIRAE.A. Caracterização genética de seis plantéis comerciais de tilápia (Oreochromis) utilizando marcadores microssatélites. Arquivo Brasileiro de Medicina Veterinaria e Zootecnia, v.58, p.87-93, 2006.

MILLER, M.P. Tools for population genetic analyses (TFPGA): a Windows program for the analysis of allozyme and molecular population genetic data. Version 1.3. Flagstaff: Northern Arizona University, 1997. 33p.

MOREIRA, A.A.; HILSDORF, A.W.S.; SILVA, J.V. da; SOUZA, V.R. de. Variabilidade genética de duas variedades de tilápia nilótica por meio de marcadores microssatélites. Pesquisa Agropecuária Brasileira, v.42, p.521-526, 2007.

NEI, M. Analysis of gene diversity in subdivided populations. Proceedings of the National Academy of Science of the United States of America, v.70, p.3321-3323, 1973.

NEI, M. Estimation of average heterozygosity and genetic distance from a small number of individuals. Genetics, v.89, p.583-590, 1978.

POVH, J.A.; LOPERA BARRERO, N.M.; RIBEIRO, R.P.; LUPCHINSKI JUNIOR, E.; GOMES, P.C.; LOPES, T.S. Importancia del monitoreo genético de programas de repoblamiento de peces mediante marcadores moleculares. Ciencia e Investigación Agraria, v.35, p.25-35, 2008a.

POVH, J.A.; RIBEIRO, R.P.; SIROL, R.N.; STREIT JÚNIOR, D.P.; LOPERA BARRERO, N.M.; VARGAS, L.; GOMES, P.C.; LOPES, T. da S. Diversidade genética de pacu do Rio Paranapanema e do estoque de um programa de repovoamento. Pesquisa Agropecuária Brasileira, v.43, p.201-206, 2008 b.

RAYMOND, M.; ROUSSET, F. An exact test for population differentiation. Evolution, v.49, p.1280-1283, 1995.

WEIR, B.S.; COCKERHAM, C.C. Estimating F statistics for the analysis of population structure. Evolution, v.38, p.1358-1370, 1984.

WILLIAMS, J.G.K.; KUBELIK, A.R.; LIVAK, K.J.; RAFALSKI, J.A.; TINGEY, S.V. DNA polymorphisms amplified by arbitrary primers are useful as genetic markers. Nucleic Acids Research, v.18, p.6531-6535, 1990.

WORKMAN, P.L.; NISWANDER, J.D. Population studies on southwestern Indian tribes. II. Local genetic differentiation in the Papago. American Journal of Human Genetic, v.22, p.24-49, 1970.

WRIGHT, S. Evolution and the genetics of populations. Chicago: University of Chicago, 1978. 580p.

YEH, F.C.; BOYLE, T.Y.Z.; XIYAN, J.M. PopGene Version 1.31: Microsoft Window-based freeware for population genetic analysis. Alberta: University of Alberta and Center for International Forestry Research, 1999.

Recebido em 12 de agosto de 2009 e aprovado em 23 abril de 2010 